\title{
Throwing Clay with Iron Fillings on the Potter's Wheel
}

\author{
Okewu Ebute Jonathan ${ }^{1,2^{*}}$ Dr. Tukur D.M. Zauro ${ }^{2}$ Dr. Adele D. Garkida ${ }^{2}$ \\ 1. Department of Visual and Creative Arts, Federal University Lafia PMB 146, Lafia, Nasarawa State, Nigeria \\ 2. Department of Industrial Design, Ahmadu Bello University, Zaria, Kaduna State Nigeria \\ *E-mail: jonathan.okewu@gmail.com
}

\begin{abstract}
Previous studies on Iron fillings and Clay have shown that Iron fillings is of significant importance in ceramic composite especially as it has to do with the reduction of shrinkage on clay and the speckle effect on clay for decorative ceramics wares. The working of Iron fillings of different aggregate sizes into clay is both a pleasant and ugly experience which is worthy of documenting. This will be important to guide a ceramist that will intend to line blend and produce wares with iron fillings and clay by throwing on the potter's wheel. Iron fillings were gotten and analysed by sieving into different aggregate sizes for experimentation on clay. Clays were also gotten and prepared into a workable consistency. Iron fillings and clay were blended together in different percentages, this was followed by throwing on the wheel. Just as iron fillings was differed in the clay, so also the effect it has on the throwing ability of the body as regard plasticity. If iron fillings is too much in the body, it becomes difficult and sometimes injurious to work on.
\end{abstract}

\section{Introduction}

Line blending is a systematic way of finding out the reactions of two different materials or mixtures of materials that can come in convenience with each other (Henrik and James, 1993).

Iron filings is perceived to be able to come in convenience with clay since grog could also be used in clay body. Throwing method of production as applied, gave a good opportunity to really feel the effect of iron on the body as it affected plasticity which ultimately is needed for pulling and shaping of wares on the potter's wheel. (Jonathan et'ail, 2014).

Wheel throwing to make clay objects was developed in China at least as early as 3500 BC. This involves centering a ball of clay on a table that is turned by kicking a weighted wheel, or operating a treadle. The form is shaped by the potters hands, but is perfectly symmetrical, because of the turning of the wheel as he shapes the clay. Throwing is the method most commonly used today for handmade ceramics. This techniques is very much mechanical. A wheel that is mainly made for making pots is used for throwing clay with iron fillings. (Jonathan, 2014)

Iron filings are mostly a byproduct of the grinding, filing, or milling of finished iron products, so their history largely tracks the development of iron. For the most part, they have been a waste product. While the Free Dictionary (2014) defines iron fillings as a fragment of iron rubbed off by the use of a file. Cast iron which has melting temperatures closely relating usually ranging from 1150 to $1200{ }^{\circ} \mathrm{C}\left(2102\right.$ to $\left.2192^{\circ} \mathrm{F}\right)$, which is about $300{ }^{\circ} \mathrm{C}\left(572{ }^{\circ} \mathrm{F}\right)$ lower than the melting point of pure iron, is used widely in the automotive and heavy equipment industries for structural components such as engine, brake, suspension, and steering parts. Cast iron is formed by adding carbon (graphite) to steel. The characteristics of cast iron are formed during solidification and once solid cannot be changed through further heating (Nikon, 2011)

\section{Methodology}

Population of this study is comprised of Kaolin, Secondary Clay and Iron Filings. Clay were obtained in the form of fine grain materials with some lumps. The kaolin and clay were soaked in different bins but in the same quantity of 50/50 for two weeks and this was followed by blunging the clay and Kaolin together to form a homogenous mixture which was sieved to improve the clays plasticity resulting in the formation of the clay body. Iron filings were obtained in the form of semi powder in different particle sizes. It was subjected to analyses by sieving with graduated mesh of three hole sizes of 1.18 millimeter, 600 micron, and 300 micron. The largest aggregate size of $1.18 \mathrm{~mm}$ took $60 \%$ of the whole constituent, $600 \mu \mathrm{m}$ became the second largest aggregate size with $24 \%$ of the constituent, and $300 \mu \mathrm{m}$ took $16 \%$. Clay and iron fillings were blended by kneading. Throwing method of was adopted in production. The clay was further moistened to be a little softer than the usual throwing hardness because of the introduction of iron fillings. 
Table 1: Compositions containing clay and iron fillings in different percentages

\begin{tabular}{|c|c|c|c|c|}
\hline Samples & $\mathrm{A}$ & $\mathrm{B}$ & $\mathrm{C}$ & $\mathrm{D}$ \\
\hline $\begin{array}{c}\text { Stone ware Clay } \\
\text { / Iron Filings }\end{array}$ & $95 / 5$ & $90 / 10$ & $85 / 15$ & $80 / 20$ \\
\hline & $95 / 5$ & $90 / 10$ & $85 / 15$ & $80 / 20$ \\
& $95 / 5$ & $90 / 10$ & $85 / 15$ & $80 / 20$ \\
\hline & $95 / 5$ & $90 / 10$ & $85 / 15$ & $80 / 20$ \\
\hline
\end{tabular}

Alphabets A - B represents the different aggregate sizes, percentages 95/5 - 80/20 is for the ratio of clay body and iron filings.

\section{Results and Discursion}

Just as the percentages of clay and iron filings differs, so their behavior in the throwing. Breakage occurred according to the amount of iron filings in the body during shaping. Each aggregate size of iron filings had peculiar actual texture feel when it was thrown and plasticity was affected as the quantity of iron filings changes in each body.

Throwing with $1.18 \mathrm{~mm}$ aggregate: this aggregate size was varied from 95/5\% up to 80/20\% clay and iron filings. At $95 \%$ clay and $5 \%$ iron filings, there was enough plasticity to work with, there was no problem centering of the clay, pulling, and shaping as the clay was still obedient to instructions on the wheel.

The composition of $90 \%$ clay and $10 \%$ iron filings in this aggregate size proved little different from the 95/5\% composition, the reduction in plasticity could be felt, the coarseness and quantity of iron could also be felt. Reasonable amount of plasticity still abound for reasonable centering, pulling and shaping of clay on the wheel.

Unlike the two foregoing compositions, $85 \%$ clay and $15 \%$ iron filings proved difficult as the clay became heavy, had little plasticity to work with, and entails great skill to be able to manipulate on the wheel. Cylinders can only be conveniently made out of this composition as there were breakages on the body in attempts to shape the clay, which is as a result of much iron filings in the body.

Composition of $80 \%$ clay and $20 \%$ iron filings became the most difficult of them all. The clay became very heavy, very insignificant plasticity to work with and left with no option other than managing to make a cylinder and little shaping ability. The coarseness of the aggregate size of iron filings could be injuriously felt.

Throwing with $600 \mu \mathrm{m}$ aggregate size; the basic difference between the throwing of compositions from this aggregate size of iron filings and the forgoing lies with the coarseness of the aggregate size, while the former is very coarse to the touch especially when it is much in the body, $600 \mu \mathrm{m}$ size is less coarse to the touch and allows for more blending into the clay body.

Like the other, the less the iron filing in the body, the more the plasticity to work with and the more the iron filings in the body, the less the plasticity to work with. $85 / 15 \%$ clay and iron with $80 / 20 \%$ clay and iron throwing from this aggregate size all showed breakages during shaping due to less plasticity as a result of overwhelming iron filings in the clay bodies.

Throwing with $300 \mu \mathrm{m}$ aggregate size; this is the finest size of aggregate of iron filings, this felt and showed almost homogenous mix with clay during throwing. Every other attributes were the same during throwing as the foregoing two.

Throwing with Mix aggregate sizes; the iron filings here were not sieved and had the combination of all the aggregate sizes. Both homogeneity and coarseness of the composition could be felt and seen during throwing. The quantity of iron filings in clay had a lot influence in testing the workability of composition of clay and iron filings as far as throwing method of production is concern. Throwing were majorly to determine the suitability of iron filings and clay for throwing production.

\section{Conclusion}

Throwing method of production employed was convenient and stress free though with good amount of skill to be able to handle the mixture of clay and iron filings on the wheel. The technique of moistening the stone ware clay and making it softer than the normal throwing clay before throwing proved effective as it prevented breakage of the body that could have occurred on the wheel if the blend was not properly moistened. The immediate throwing of the blend guarded against rust of the iron filings.

Throwing method of production as applied in the research gave a good opportunity to really feel the effect of iron on the body as it affected plasticity which ultimately is needed for pulling and shaping of wares on the wheel.

The use of $20 \%$ coarse aggregate $(1.18 \mathrm{~mm})$ size of iron filings with $80 \%$ clay on the wheel was injurious to the palms in attempt to force the centering of the clay body on the wheel. Potters can desist from using this proportion or can be used but with great care. 


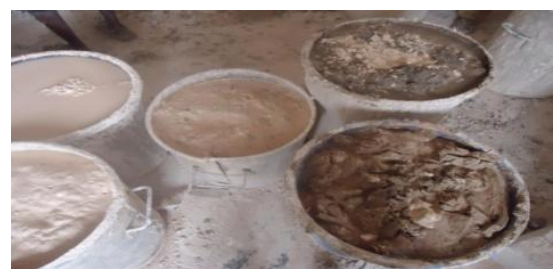

Plate 1: soaked clay and kaolin in bins

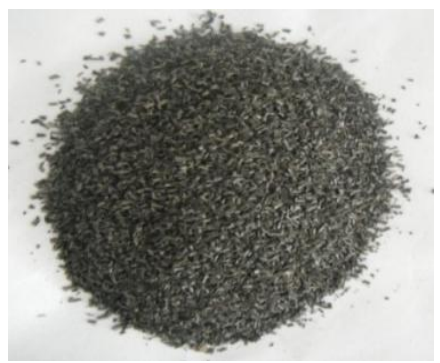

Plate 2: $1.18 \mathrm{~mm}$ aggregate sizes of iron filings

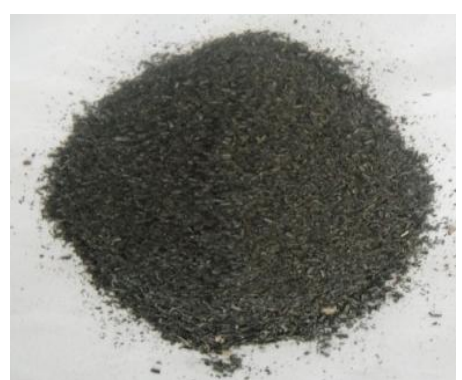

Plate 4: un- sieved aggregate of iron filings

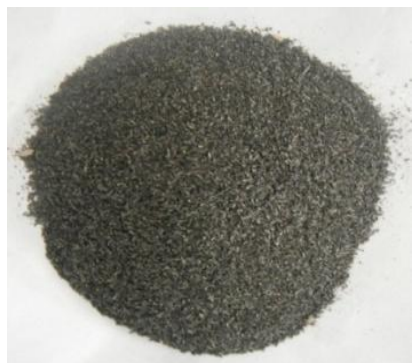

Plate 3: $600 \mu \mathrm{m}$ aggregate sizes of iron filings

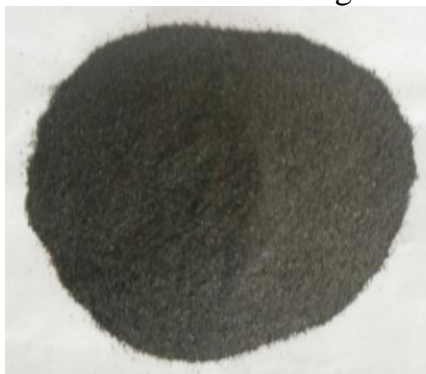

Plate 5: $300 \mu \mathrm{m}$ aggregate sizes of iron filings

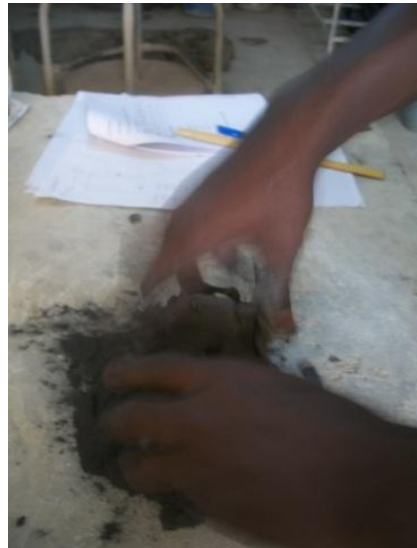

Plate 7: Blending ironfilings into clay by kneading

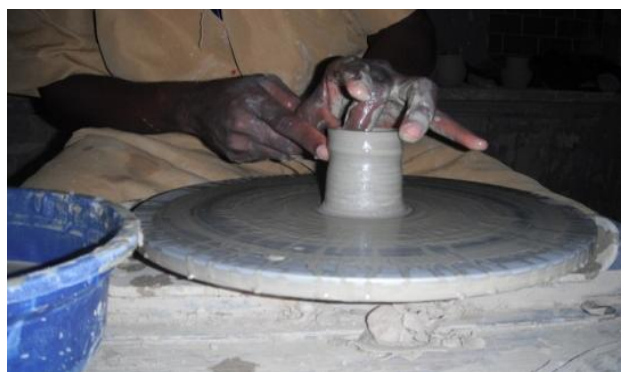

Plate 8: Throwing of clay and iron filings on the potter's wheel 


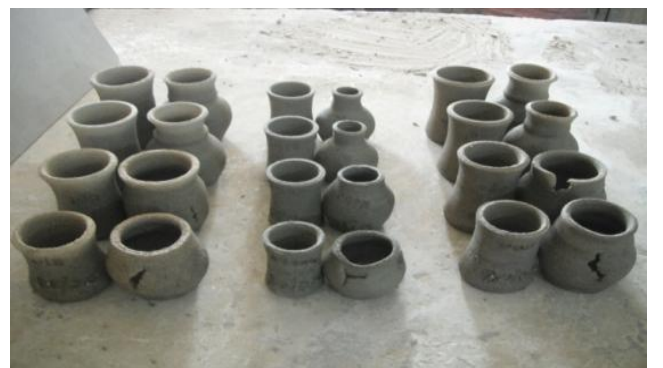

Plate 9: Outcomes of throwing of clay and iron filings at green ware stage

\section{References}

[1]. Henrik N. James D. (1993), glazes - for the self-reliant potter, retrieved 30 July, 2014 http://www.gateinternational.org/documents/publications/webdocs/pdfs/g17gle.pdf. p. 86

[2]. Jonathan O.E. , Zauro T.D.M, Garkida A.D. (2014), Incorporating Iron Filings from Zaria Nigeria into Clay Body for the Production of Decorative Ceramics. Arts and Design Studies ISSN 2224-6061 (Paper) ISSN 2225-059X (Online) Vol.19, 2014. www.iiste.org

[3]. Jonathan O.E. (2014), Manual Potter's Wheel Efficiency in Ceramics Production in Nigeria

[4]. IOSR Journal Of Humanities And Social Science (IOSR-JHSS) Volume 19, Issue 2, PP 01-05 e-ISSN: 2279-0837, p-ISSN: 22790845. www.iosrjournals.org

[5]. Nikon (2011), Cast iron nodularity and flake analysis, retrieved 30 July, 2014.

[6]. http://www.nikoninstruments.com/Applications/Industrial/Material-Analysis/Cast-iron-nodularity-and-flake-analysisThe Free Dictionary (2014), Iron fillings, retrieved 1 August, 2014 http://www.thefreedictionary.com/iron+filing

[7]. Wikipedia (2014), Iron filings, retrieved 1 August, 2014 http://en.wikipedia.org/wiki/Iron_filings 